\title{
Projeto Acrobatas: processo de criação de uma apresentação coreográfica
}

\author{
Alícia Marmitt ${ }^{*}$ \\ Cristina Borges Cafruni**
}

\begin{abstract}
Resumo:
O Projeto Acrobatas é uma ação de extensão desenvolvida no Colégio de Aplicação que oferece a prática da Ginástica Para Todos para os alunos do colégio e da comunidade. Este relato teve como objetivo descrever o processo de criação de uma apresentação coreográfica do Projeto Acrobatas. As aulas ocorreram em um encontro por semana, com turmas divididas em duas faixas etárias, de 7 a 10 anos e de 11 a 13 anos. Para o processo de criação coreográfica, foram realizadas atividades como o laboratório temático de movimentos, que envolveu a participação e a interação dos alunos. A escolha do tema da coreografia ocorreu com base na observação do interesse dos alunos. Concluiu-se que a Ginástica Para Todos promoveu um incremento para além do desenvolvimento motor dos alunos, pois possibilitou trabalhos multi/interdisciplinares. Através do processo de criação coreográfica foram desenvolvidas diversas competências, entre elas, a cooperação e a criatividade.
\end{abstract}

\section{Palavras-chave:}

Ginástica. Ginástica Para Todos. Criatividade. Crianças. Coreografia.

\begin{abstract}
:
The Projeto Acrobatas is an extension action developed at the College of Application that offers the practice of Gymnastics For All to students of the school and the community. This report aimed to describe the process of creating a choreographic presentation of the Acrobats Project. Classes took place in one meeting per week, with classes divided into two age groups, from 7 to 10 years old and from 11 to 13 years old. For the choreographic creation process, activities were carried out such as the thematic movement laboratory, which involved student participation and interaction. The choreography theme was chosen based on the observation of the students' interest. It was concluded that Gymnastics for All promoted an increase beyond the motor development of students, as it enabled multi/interdisciplinar interventions. Through the choreographic creation process, several skills were developed, including cooperation and creativity.
\end{abstract}

\section{Keywords:}

Gymnastic. Gymnastics For All. Creativity. Children. Choreography.

\footnotetext{
* Graduanda do curso de Licenciatura em Artes Visuais da UFRGS. E-mail: aliciamarmitt@hotmail.com. ORCID iD: http://orcid.org/0000-0001-9553-3712.

** Doutora em Saúde Coletiva pela UNISINOS. Professora de Educação Física do Colégio de Aplicação da UFRGS. E-mail: ccafruni@hotmail.com. ORCID iD: http://orcid.org/0000-0002-3568-0785.
} 


\section{Introdução}

O Projeto Acrobatas é uma atividade de extensão da Universidade Federal do Rio Grande do Sul (UFRGS) desenvolvida no Colégio de Aplicação desde 2007, que tem como objetivo oferecer a prática da Ginástica Para Todos (GPT) para os alunos do colégio e da comunidade. A extensão universitária consiste em um "processo educativo, cultural e científico que articula, amplia, desenvolve e realimenta o ensino e a pesquisa, propiciando a interdisciplinaridade e viabilizando a relação transformadora entre Universidade e sociedade” (UFRGS, 2019, p. 1). São pressupostos para se constituírem atividades de extensão as intervenções que envolvam diretamente as comunidades externas às instituições de Ensino Superior e que estejam vinculadas à formação do estudante (BRASIL, 2018). Assim, consistente com a regulamentação das atividades de extensão da Universidade, ao longo de uma década de desenvolvimento o Projeto Acrobatas atendeu aproximadamente 300 alunos, sendo $20 \%$ da comunidade externa à UFRGS. Nesta caminhada, o projeto contou também com a participação de 13 bolsistas de extensão, que são alunos de cursos de graduação da UFRGS dedicados a desenvolver o projeto através da sua participação em várias etapas: planejamento, execução e processo avaliativo.

Um dos principais propósitos do Projeto Acrobatas é promover a ginástica na escola. Sabe-se que apesar de compor as diretrizes da Educação Física escolar (BRASIL, 1998, 2017), a ginástica se faz pouco presente nos currículos e no universo cultural de crianças e adolescentes brasileiros (OTSUKA, 2012; MARIANO; PARENTE; JUNIOR, 2019; SANTOS et al., 2018). Sendo assim, a oferta de aulas de ginástica no turno escolar inverso, visa oportunizar a sua prática àqueles que a não conhecem, e constitui um espaço de aprofundamento para aqueles que se identificam com este tipo de prática corporal. A escolha da GPT para o desenvolvimento da ginástica na escola, se deu por esta modalidade apresentar um caráter plural, ou seja, suas características englobam a combinação de diversos tipos de ginástica, a ausência de regras rígidas e do caráter competitivo e a inclusão de alunos de diferentes níveis de aprendizagem (AYOUB, 2004). Sendo classificada como ginástica de demonstração, vários elementos artísticos ou acrobáticos podem compor esta prática, que culmina em uma apresentação coreográfica temática (SANTOS, 2001). Destaca-se que a apresentação temática pode se constituir um processo de construção coletiva, onde os integrantes participam ativamente com criações, observações e reflexões sobre a coreografia elaborada (SANTOS et al., 2018; SOARES; ALMEIDA; BORTOLETO, 2016; BATISTA, 2019). Todos estes aspectos mencionados fortalecem e justificam a inclusão da GPT no contexto escolar.

A composição coreográfica, faz parte do universo das artes e das ginásticas (SCARABELIM; TOLEDO, 2016). Poucos estudos demonstraram como ocorreu o processo de elaboração coreográfica nos grupos de GPT.

Lifante e Brant (2016) descreveram como realizaram este processo pedagógico para a elaboração da coreografia Natureza em Equilíbrio, desenvolvido pelo Grupo de Pesquisa e Extensão em Ginásticas, do Instituto Federal do Sul de Minas. O início do processo de criação ocorreu com rodas de conversas sobre o tema, que foi sugerido pelo grupo. Em seguida os integrantes participaram de vivências corporais de forma livre, com a exploração individual de várias possibilidades de expressão corporal, que foram posteriormente apresentadas para o grupo. A prática foi sendo orientada para que as experiências e criações fossem compartilhadas em pequenos grupos, aumentando o número de integrantes até chegar ao grupo maior, onde todos deveriam experienciar as sugestões dos colegas. Foram mencionadas algumas dificuldades, como a extrapolação do tempo para finalizar a composição coreográfica, em função de todas as propostas serem discutidas, e as divergências de ideias e opiniões, que foram resolvidas pelo grupo. Todos os integrantes participaram efetivamente do processo de criação coreográfica, puderam expressar suas ideias e participaram de acordo com as suas condições.

Outro estudo fez uma análise nas composições coreográficas de dois grupos de GPT (Gymnarteiros e Gymnsup) com base nas fases sistematizadoras da criatividade: apreensão - despertar do interesse; preparação - levantamento de dados, por meio de pesquisa; incubação - reflexão do material; iluminação - exploração, teste de movimentos, fase em que o trabalho coreográfico começa a se organizar; verificação - momento de escolha do que se mantém (KNELLER, 1978). A análise concluiu que os grupos tiveram suas fases iniciais de composição semelhantes, mas que foram se transformando de acordo com os objetivos do grupo. 
Os autores defendem a atuação do professor como mediador, e salientam que o protagonismo dos integrantes do grupo contribuiu para a formação de cidadãos autônomos e críticos (FURTADO; CARBINATTO, 2018).

Com abordagem semelhante, o grupo de ginástica da Universidade de Campinas, propôs uma participação coletiva em todas as fases de elaboração coreográfica. A proposta metodológica sugeriu vários momentos com o objetivo de promover o aumento da interação social, ampliar a vivência dos saberes e das habilidades ginásticas, explorar os materiais disponíveis e, por fim, demonstrar as criações corporais dos integrantes do grupo e observar as elaborações dos colegas. Para que proposta tenha sucesso, os autores destacaram que os conteúdos devem ser escolhidos de acordo com interesses e expectativas dos praticantes. Ressaltam também, que a condução das atividades que favorecem a ampla participação do grupo faz diminuir, gradativamente, a necessidade de direcionamento do professor (SOARES; ALMEIDA; BORTOLETO, 2016).

Considerando a importância que estes relatos representam para a produção de conhecimentos na área, este estudo teve como objetivo descrever o processo de criação de uma apresentação coreográfica do Projeto Acrobatas.

\section{Metodologia}

A experiência relatada foi desenvolvida no período de maio a novembro de 2019. As aulas ocorreram no Colégio de Aplicação da UFRGS, em um encontro semanal de 60 minutos, com turmas divididas em duas faixas etárias, de 7 a 10 anos (Alfas) e de 11 a 13 anos (Amoras). Cada turma tinha, em média, 15 alunos. Com exceção de dois alunos, a maioria era iniciante na modalidade. As aulas ocorreram em uma sala de atividades múltiplas. Foram utilizados materiais como tatames, colchões, trampolim, banco sueco e fitas. Para as duas turmas, o processo de criação coreográfica teve duração de aproximadamente quatro meses. As aulas foram adaptadas da proposta de Santos (2001), onde são realizados elementos da ginástica com e sem aparelhos, laboratórios de movimentos e desenvolvimento da apresentação coreográfica. O processo de criação coreográfica foi fundamentado no interesse e na identidade dos grupos do Projeto Acrobatas, e contou com a participação dos alunos (TAPIA; FITA, 1999; SOARES, 2010; AYOUB, 2004; SOARES; ALMEIDA; BORTOLETO, 2016). As atividades foram planejadas e registradas em uma ficha (Quadro 1). Utilizou-se a avaliação diagnóstica e formativa para avaliar o processo de ensino-aprendizagem (CARVALHO, 1994). Nas primeiras aulas, a avaliação diagnóstica serviu tanto para compreender quais movimentos e ações da ginástica os alunos já conheciam, quanto para perceber qual era a identidade do grupo, fator que contribuiu posteriormente no processo de criação coreográfica. Já a avaliação formativa, ocorreu em todas as aulas serviu para regular o processo de ensino-aprendizagem, pois a mesma ocorre como resultado da interação entre os alunos, professor-aluno e intrínseca (CARVALHO, 1994). Os instrumentos utilizados para avaliar foram a observação dos alunos, ficha de registros das atividades feitas pelo professor e registros por escrito ou através de desenhos realizados pelos alunos.

Quadro 1 - Ficha de registro das atividades (exemplos)

\begin{tabular}{|l|l|l|}
\hline Conteúdos & \multicolumn{1}{|c|}{ Data: 01/08 } & \multicolumn{1}{c|}{ Data: 08/08 } \\
\hline Aquecimento lúdico & Brincadeira pega-pega da montanha & $\begin{array}{l}\text { Movimentos de danças } \\
\text { Caminhadas direcionadas entre brisa, } \\
\text { ventania e furacão. }\end{array}$ \\
\hline $\begin{array}{l}\text { Exercícios de } \\
\text { flexibilidade }\end{array}$ & Carpado, Cachorrinho, Espacate frontal & $\begin{array}{l}\text { Carpado, Cachorrinho, } \\
\text { Espacate frontal e lateral }\end{array}$ \\
\hline Acrobacias & $\begin{array}{l}\text { Rolamento para frente na rampa, iniciação } \\
\text { à ponte, estrelinha e parada de cabeça }\end{array}$ & $\begin{array}{l}\text { Rolamento para trás na rampa } \\
\text { Rolamento para frente, Saltos no trampolim }\end{array}$ \\
\hline $\begin{array}{l}\text { Formações } \\
\text { corporais }\end{array}$ & $\begin{array}{l}\text { Formação do grupo em V } \\
\text { Pirâmides em duplas }\end{array}$ & $\begin{array}{l}\text { Formação do grupo em V } \\
\text { Início da coreografia, Pirâmides em trios }\end{array}$ \\
\hline Observações & $\begin{array}{l}\text { Alguns alunos tiveram dificuldade para } \\
\text { realizar a parada de cabeça }\end{array}$ & Os alunos sugeriram pirâmides \\
\hline
\end{tabular}

Fonte: Elaborado pelas autoras. 


\section{Resultados e discussão}

As aulas do Projeto Acrobatas foram divididas em duas etapas. A primeira etapa, teve como objetivo principal a aprendizagem e o desenvolvimento de elementos básicos da ginástica e das capacidades motoras e coordenativas (LEGUET, 1987). Na segunda etapa, ocorreu o processo de criação da apresentação coreográfica, desenvolvido através de diversas práticas que objetivaram estimular a criatividade dos alunos, e assim, cooperar coletivamente na criação da apresentação.

Na primeira etapa da turma Alfas, as aulas iniciavam com propostas de aquecimento lúdico, que progrediam de nível de dificuldade de acordo com o aprendizado dos alunos. Brincadeiras tradicionais foram adaptadas com a utilização de exercícios da ginástica. Por exemplo, a conhecida brincadeira pega-pega foi transformada em "Pique-Montanha". Nesta brincadeira, o participante que era pego pelo caçador deveria ficar na posição de quatro apoios em decúbito ventral, a qual era chamada de "montanha" e, posteriormente, na posição do elemento ginástico Ponte, até que um colega chegasse para salvá-lo, passando por baixo da Ponte. Foi uma atividade muito solicitada pelas crianças, e serviu para avaliação diagnóstica dos alunos (CARVALHO, 1994). Outras adaptações de brincadeiras tradicionais foram feitas, como no caso de “Quantos Passos Posso Dar?”. Nesta brincadeira, os participantes formavam duplas e, no lugar de solicitar passos de formiga ou elefante, executavam os movimentos ginásticos aprendidos até o momento. Depois do aquecimento, era elaborado um circuito com móveis que havia na sala, transformando-os em aparelhos da Ginástica Artística. Dessa forma, um banco extenso transformou-se em trave, e uma mesa coberta com tatame, colchão e trampolim representou o salto sobre a mesa.

Um pouco antes de iniciar a criação coreográfica, na segunda etapa de desenvolvimento do projeto, os participantes do grupo Alfas vivenciaram um laboratório de experimentos corporais sobre "o vento", que marcou o início dos estudos para possíveis temáticas e dinâmicas para a apresentação final. Envolvendo atividades que requisitaram a participação e a interação dos alunos, cada dupla criou três movimentos sobre algo incolor, inodoro e abstrato, como as variações de brisa, ventania e furacão. Depois de alguns minutos, uma atmosfera teatral se instalou, onde a música diminuía e a plateia exercia o silêncio e atenção máxima para descobrir qual das três variações estava sendo apresentada pelos colegas. Essas explorações feitas nos laboratórios auxiliaram posteriormente na criação do tema, pois os alunos já tinham sentido no corpo como era representar algo, muitas vezes abstrato, através de movimentos.

Os depoimentos da turma Alfas demonstraram a satisfação dos alunos com o tema "o vento". No entanto, seria preciso definir um tema que representasse a turma a partir de uma proposta que partisse do grupo. Foi realizado um experimento em laboratório de desenho, onde se estabeleceu uma emoção e o participante deveria representá-la através de uma imagem, para os colegas adivinharem. Assim, percebeu-se que essa turma gostava de jogos de abstrações e temas que pudessem usar a imaginação. Entre temáticas que surgiram, "as cores" foi a que mais agradou ao grupo. Dentro deste tema, foi utilizado na coreografia um grande tecido com desenho de latas de tintas. A interação com algo material foi divertida e desafiadora, pois uma coreografia requer atenção para fazer tudo em seu tempo. A montagem coreográfica se desenvolveu a partir de ideias sugeridas pelos alunos e dinâmicas e composições corporais elaboradas pela professora. Como o grupo possuía baixa faixa etária, em muitos momentos da coreografia foi permitido que eles criassem seus movimentos rítmicos, ou optassem por diferentes elementos ginásticos, sem que todos os participantes precisassem fazer o mesmo. Esta estratégia permitiu estimular a criatividade dos alunos e respeitar as limitações de cada um, o que constitui uma característica da GPT ao favorecer a inclusão dos alunos (AYOUB, 2004). Por fim, foi proposta uma oficina de criação plástica, onde o grupo escolheu um figurino monocromático que foi utilizado na apresentação.

Estar atento ao comportamento dos alunos ajudou a compreender as motivações e interesses particulares de cada turma no processo de aprendizado (TAPIA; FITA, 1999). Com isso, a série de público juvenil Stranger Things foi o tema para a apresentação do grupo Amoras. O processo de escolha ocorreu naturalmente a partir de um grupo de alunas que frequentemente conversavam sobre a série em diversos momentos das aulas. Após a decisão do tema, foi escolhida a música que melhor descrevesse a situação 
que seria representada pelo grupo. O processo de criação se moldou a partir dessa conexão com os alunos em se apropriar do gosto coletivo, e a partir disso adaptar para uma apresentação coreográfica acessível ao nível de todos os alunos. A coreografia do grupo Legacy Dance Academy ${ }^{1}$, disponível na internet, serviu de inspiração para o início do trabalho. De acordo com Dantas (1997, p. 53), muitos aspectos são significativos em uma coreografia: "[...] o tema a que a coreografia está relacionada ou deseja abordar, a música ou sua ausência, o figurino, a luz, o cenário e, é claro, os movimentos e gestos executados pelos bailarinos". Por isso, buscou-se especialmente referências de movimentos e gestos e alguns elementos mais cênicos como figurino e maquiagem que pudessem contribuir para o trabalho, uma vez que a apresentação não seria realizada em um palco, onde a iluminação ou cenário fossem essenciais. Algumas opções foram sugeridas pelos professores: a composição coreográfica com referências ao jazz, e a inclusão movimentos da ginástica rítmica e acrobática; a música, que precisava identificar o tema da série e ser automaticamente reconhecido pela plateia; e por fim, o figurino de malha justa, que auxiliaria nas movimentações.

Essa estrutura inicial de ideias auxiliou a organizar o que traria mais sentido para a coreografia, e assim, os ensaios começaram a ocupar a maior parte do tempo da aula, caracterizando a segunda etapa do processo. As aulas iniciavam com exercícios de aquecimento e alongamentos, e com a repetição de movimentos gímnicos ou exercícios de coordenação motora e rítmica, a fim de aprimorar a sincronicidade do grupo com a música. Realizou-se um laboratório de fitas da ginástica rítmica, onde no primeiro encontro foram confeccionadas as fitas. As alunas receberam a orientação para a sua montagem, utilizando argolas, régua, tesoura e graveto de madeira, potencializando um elemento cênico e orgânico ao fazer referência ao tema "Stranger Things". Em seguida, foram feitas aulas práticas de manuseio da fita com formas abstratas de movimentações como giros, espirais, ondulações e caminhadas.

Na turma Amoras, a maior participação dos alunos no processo de criação coreográfica se deu nos momentos de formação corporal em duplas ou grupos, os quais chamamos de "pirâmides". Com o passar das aulas, alguns alunos se ausentaram e outros saíram definitivamente do projeto, levantando desafios onde o raciocínio rápido e a improvisação criativa foram despertados no grupo. Ajustes nas composições, troca de lugares e adaptações foram necessárias para a continuidade da coreografia, visto que faltavam poucos encontros até a apresentação final. A participação e a atenção dos alunos foram essenciais para lembrar os lugares que os colegas ocupavam, suas duplas em movimentos acrobáticos e principalmente, para repensar no coletivo as melhores formas de reestruturar a coreografia. Sugestões para retirar um movimento não convencional executado na coreografia também foram mencionadas pelos alunos, por receio do julgamento dos colegas da escola que iriam assistir. Mas, ao invés de trocar a estrutura do movimento, foram desenvolvidas as intenções de representação do movimento, potencializando a proposta inicial. Também foi realizada uma oficina de maquiagem artística, onde foram debatidos nas aulas quais pigmentos e penteados deveriam representar uma temática de suspense.

\section{Considerações finais}

O processo de criação coreográfica incrementou uma consciência de corpo coletivo e cenografia para transmitir ao público a intenção do grupo. Foi um momento de extrema importância para os alunos, pois dialogou com a plateia de maneira expressiva, através dos movimentos estéticos, mas também dos sentimentos e significados criados pelos participantes. A participação dos alunos no processo de criação coreográfica exprimiu um maior significado às composições corporais.

De acordo com Alencar (1995 apud DANTAS, 1997), alguns aspectos constituem pré-requisitos para a produção criativa: a preparação do indivíduo com disciplina, dedicação e esforço consciente, o conhecimento, os traços da personalidade e as características cognitivas do indivíduo. Assim, na produção criativa, as escolhas dos professores em suas mediações no processo de ensino-aprendizagem dos alunos

1. Disponível em: https://www.youtube.com/watch?v=3SmbZ8fGYFs. Acesso em: 15 jul. 2019. 
podem ser semelhantes à atuação de um guia que já percorreu uma trilha fechada e conhece o caminho para liderar os viajantes. Não obstante, este caminho pode ser modificado através de diversas intervenções. Neste sentido, exercícios e práticas criativas realizados nas aulas foram os potencializadores de ideias para os alunos, e posteriormente agrupados e processados pelas professoras, ao agregar conhecimentos técnicos, teóricos, práticos e afetivos.

Em síntese, a participação dos alunos no processo de criação coreográfica ocorreu em diversos momentos como, na manifestação da identidade dos grupos, que colaborou para a escolha dos temas, em partes da coreografia onde os alunos podiam escolher o que dançar ou qual movimento da ginástica realizar, durante as escolhas das Pirâmides, nas opiniões sobre algum movimento de dança, nas escolhas relacionadas ao figurino e à maquiagem e, por fim, nas sugestões de adaptações da coreografia. Diferente dos relatos de outros grupos de GPT (SOARES; ALMEIDA; BORTOLETO, 2016; LIFANTE; BRANT, 2016; FURTADO; CARBINATTO, 2018), os alunos do Projeto Acrobatas não elaboraram toda a coreografia. Como fatores limitadores, consideramos a baixa faixa etária dos alunos, o tempo curto de duração das aulas e o reduzido número de encontros. Entretanto, consideramos que os momentos em que os alunos puderam participar da criação coreográfica não foram poucos, e tiveram importância na construção da sua autonomia. Gradativamente, estes momentos contribuem na construção de uma cultura de participação, que vai sendo ampliada de acordo com a maturidade do grupo.

A GPT promoveu um incremento para além do desenvolvimento motor dos alunos, pois possibilitou uma riqueza de trabalhos multi/interdisciplinares. Através das atividades propostas no Projeto Acrobatas foram desenvolvidas diversas competências, entre elas a cooperação e a criatividade. A prática da GPT permitiu pensar o corpo como obra, objeto artístico estruturado no encontro e apresentado em cena para o público. Ofereceu pontos de acesso ao olhar poético do movimento, desde o olhar ao caminhar pela sala às acrobacias e estéticas que podem transmitir sensações.

\section{Referências}

AYOUB, Eliana. Ginástica Geral e Educação Física Escolar. Campinas: Editora da UNICAMP, 2004.

BATISTA, Mellina Souza. Extensão universitária: análise dos grupos de ginástica para todos. 2019. 96 f. Dissertação (Mestrado em Estudos Socioculturais e Comportamentais da Educação Física e Esporte) - Escola de Educação Física e Esporte, Universidade de São Paulo, São Paulo, 2019.

BRASIL. Ministério da Educação. Base Nacional Curricular Comum. Brasília, DF: MEC, 2017. Disponível em: http:// basenacionalcomum.mec.gov.br/images/BNCC_EI_EF_110518_versaofinal_site.pdf. Acesso em: 25 jun. 2020.

BRASIL. Secretaria da Educação Fundamental. Parâmetros Curriculares Nacionais: educação física. Brasília, DF: MEC/SEF, 1998.

BRASIL. Ministério da Educação. Resolução nº 7, de 18 de dezembro de 2018. Estabelece as Diretrizes para a Extensão na Educação Superior Brasileira e regimenta o disposto na Meta 12.7 da Lei no 13.005/2014, que aprova o Plano Nacional de Educação - PNE 2014-2024 e dá outras providências. Diário Oficial da União: seção 1, Brasília, DF, p. 49-50, 19 dez. 2018. Disponível em: https://www.ufrgs.br/prorext/wp-content/uploads/2019/03/Diretrizes-Resol.07-2018-CNE.pdf. Acesso em: 30 jun. 2020.

CARVALHO, Lídia Madalena Damas. Avaliação das aprendizagens em Educação Física. Boletim Sociedade Portuguesa Educação Física, Portugal, n. 10/11, p. 135-151, 1994.

DANTAS, Monica Fagundes. Dança e linguagem: a construção de sentidos coreográficos. Revista Perfil, Porto Alegre, n. 1, p. 52-66, 1997.

FURTADO, Lorena Nabanete dos Reis; CARBINATTO, Michele Viviene. O processo criativo e colaborativo na composição coreográfica de ginástica para todos. In: FÓRUM INTERNACIONAL DE GINÁSTICA PARA TODOS, 9., 2018, Campinas. Anais [...]. Campinas: FEF/UNICAMP; Limeira: FCA/UNICAMP; Várzea Paulista: Fontoura; São Paulo: SESC, 2018. Disponível em: https://www.forumgpt.com/2018/arquivos/anais/09-forum-internacional-de-gpt-2018.pdf. Acesso em: 3 set. 2019.

KNELLER, George. Arte e Ciência da Criatividade. 5. ed. São Paulo: Ibrasa, 1978. 
LEGUET, Jacques. As ações motoras em ginástica esportiva. São Paulo: Editora Manole, 1987.

LIFANTE, Daniely Gauna Ramos; BRANT, Tuffy Felipe. Natureza em equilíbrio. In: FÓRUM INTERNACIONAL DE GINÁSTICA PARA TODOS, 8., 2016, Campinas. Anais [...]. Campinas: FEF/UNICAMP: SESC, 2016. Disponível em: https://www.forumgpt.com/2018/arquivos/anais/08-forum-internacional-de-ginastica-geral-2016.pdf. Acesso em: 1 set. 2019.

MARIANO, Misma Lima; PARENTE, Maria Larissy da Cruz; JUNIOR, Jayme Felix Xavier. O ensino da ginástica na Educação Física: uma revisão sistemática. Motrivivência, Florianópolis, v. 31, n. 60, p. 1-17, out./dez. 2019.

OTSUKA, Marcos. Pluralidade corporal e ginástica: o contexto escolar e materiais alternativos. 2012. 113 f. Dissertação (Mestrado em Ambiente e Desenvolvimento) - Centro Universitário UNIVATES, Lajeado, 2012.

SANTOS, José Carlos Eustáquio dos. Ginástica Geral: elaboração de coreografias e organização de festivais. Jundiaí: Fontoura, 2001.

SANTOS, Thyago Thacyano de Souza et al. A Ginástica Para Todos nas aulas de Educação Física: um estudo de caso. Conexões: Educação Física, Esporte e Saúde, Campinas, v. 16, n. 4, p. 450-467, out./dez. 2018.

SCARABELIM, Maria Letícia Abud; TOLEDO, Eliana. Proposal of analytical records for choreographic compositions in gymnastics for all. Revista Brasileira de Educação Física e Esporte, São Paulo, v. 30, n. 1, p. 159-170, jan./mar. 2016.

SOARES, Priscila Gonçalves. Diálogos com a ginástica. EFDeportes.com, Revista Digital, Buenos Aires, v. 15, n. 150, 2010. Disponível em: https://www.efdeportes.com/efd150/dialogos-com-a-ginastica.htm. Acesso em: 6 jun. 2011.

SOARES, Daniela Bento; ALMEIDA, Tabata Larissa; BORTOLETO, Marco Antonio Coelho. Autonomia, criatividade e o processo de construção coletiva na Ginástica Para Todos. In: MIRANDA, Rita de Cassia Fernandes; EHRENBERG, Mônica Caldas; BRATIFISCHE, Sandra Aparecida. Temas emergentes da Ginástica Para Todos. Várzea Paulista: Fontoura, 2016.

TAPIA, Jesús Alonso; FITA, Enrique Caturla. A motivação em sala da aula: o que é, como se faz. São Paulo: Loyola, 1999.

UNIVERSIDADE FEDERAL DO RIO GRANDE DO SUL (UFRGS). Conselho de Ensino, Pesquisa e Extensão. Resolução $n^{\circ} 75$, de 4 de dezembro de 2019. Aprova normas gerais para atividades de Extensão Universitária na Universidade Federal do Rio Grande do Sul. Porto Alegre: CEPE, 2019. Disponível em: https://www.ufrgs.br/prorext/wp-content/ uploads/2020/05/Res-75-Normas-Gerais-para-Atividades-de-Extensao-PAGINA.pdf. Acesso em: 30 jun. 2020.

Data de submissão: 15/06/2020

Data de aceite: $26 / 07 / 2020$ 